\title{
The role of sacral laminoplasty in the management of spina bifida and sacral cystic lesions: case series
}

\author{
${ }^{*}$ Yu-Ning Chen, MD, ${ }^{1}$ Shih-Hung Yang, MD, PhD, ${ }^{1}$ Sheng-Che Chou, MD, ${ }^{1-3}$ and \\ Meng-Fai Kuo, MD, PhD' \\ 1Division of Neurosurgery, Department of Surgery, National Taiwan University Hospital, National Taiwan University College \\ of Medicine, Taipei; 'Division of Neurosurgery, Department of Surgery, National Taiwan University Hospital Yun-Lin Branch, \\ National Taiwan University College of Medicine, Yunlin; and ${ }^{3}$ Graduate Institute of Clinical Medicine, National Taiwan University \\ College of Medicine, Taipei, Taiwan
}

OBJECTIVE Although laminae are not viewed as essential structures for spinal integrity, in the sacrum the anatomical weakness and gravity makes it a vulnerable area for CSF accumulation and expansion. The congenital or postoperative defects of sacral laminae, such as in patients with spina bifida, make this area more susceptible to forming progressive dural ectasia, pseudomeningocele, or expansile arachnoid cyst (Tarlov cyst). In addition, adhesions between the dura and surrounding soft tissue after laminectomy can cause some local symptoms, which are difficult to relieve. The authors propose that sacral laminoplasty with titanium mesh can provide a rigid support and barrier to resolve these sacral lesions and local symptoms.

METHODS From January 2016 to December 2017, patients with progressive CSF-containing lesions in the sacral area and defective sacral laminae were included in the study. After repair of the lesion, the authors performed sacral laminoplasty with titanium mesh in each patient. Subsequently, the soft tissue and skin were closed primarily.

RESULTS A total of 6 patients were included. Four patients with repaired myelomeningocele had progressive dural ectasia. One patient with lipomyelomeningocele previously underwent detethering surgery and developed postoperative pseudomeningocele. One patient had a symptomatic Tarlov cyst. Four of these 6 cases presented with low-back pain and local tenderness. During follow-up, ranging from 13 to 37 months, all 6 patients experienced no recurrence of dural ectasia or pseudomeningocele and were free from local symptoms.

CONCLUSIONS Sacral laminoplasty with titanium mesh is a safe and effective procedure for treating progressive sacral dural ectasia and refractory pseudomeningocele, preventing CSF leakage as well as relieving local symptoms that may occur years after previous surgery for spina bifida.

https://thejns.org/doi/abs/10.3171/2019.7.FOCUS19414

KEYWORDS spina bifida; myelomeningocele; laminoplasty; sacral; cystic

$\mathrm{T}$ HE term "spina bifida" can be traced back to the 17 th century and was first documented in the book Observationes Medicae, which was written by Nicolaes Tulp. " "Spina bifida" was initially used to describe myelomeningocele, yet nowadays this term includes a variety of related disease entities. As one of the most complex birth defects, spina bifida is estimated to affect 3 babies per 10,000 live births. ${ }^{11}$ A significant portion of patients with spina bifida present with congenital sacral defects. ${ }^{11}$ Whether congenital or postsurgical, the anatomical defects in the sacral area may coexist with expansile lesions with CSF accumulation, such as in meningocele, myelomeningocele, or lipomeningomyelocele. If surgical repair is undertaken, CSF leakage, pseudomeningocele formation, and dural ectasia may complicate recovery. ${ }^{3,10}$

In addition, laminal defects can cause local discomfort. Postlaminectomy syndrome is characterized by local symptoms, such as paraspinous muscle spasm and tactile allodynia. Epidural fibrosis, which is a major cause of postlaminectomy syndrome, may account for $20 \%-36 \%$ of cases with this syndrome. ${ }^{5}$

In the past, the sacral lamina has not been considered

* Y.N.C. and S.H.Y. share first authorship of this work. 


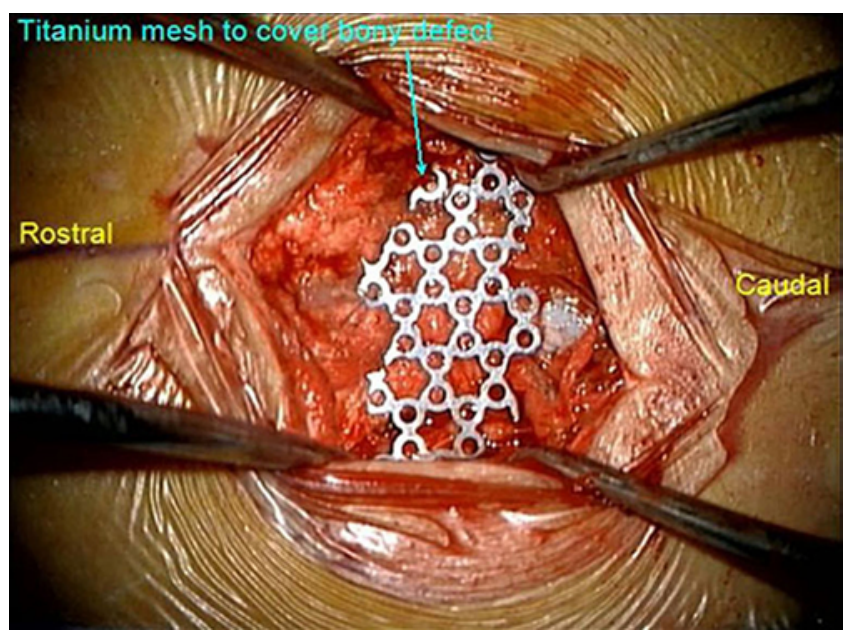

FIG. 1. Intraoperative image of sacral laminoplasty with titanium mesh.

an essential structure, and sacral laminoplasty has rarely been performed. Nevertheless, some evidence shows laminoplasty may decrease postoperative CSF leakage rates and reduce epidural fibrosis. ${ }^{14}$ Therefore, we propose that sacral laminoplasty may play a significant role in treating patients with sacral dural ectasia, pseudomeningocele, high risk of postoperative CSF leakage, or postoperative local symptoms.

\section{Methods}

From January 2016 to December 2017, patients having defective sacral laminae with progressive symptomatic enlargement of the sacral CSF-containing lesions were included in this study. Preoperative spinal MRI studies were performed to confirm the diagnoses. For the patients with spinal dysraphism (cases 1-5), ventriculoperitoneal (VP) shunt function and endoscopic third ventriculostomy (ETV) function were confirmed by clinical evaluation and brain images before surgery. During the surgical procedure, we performed midline incisions and the lesions were dissected and exposed. If there was clinical and radiological evidence of retethered spinal cord, detethering surgery was performed under intraoperative neuromonitoring. Dural incision or dural defect was repaired with primary closure using 4-0 or 5-0 Prolene suture (Ethicon Inc.), and reinforced with paraspinal muscle graft if it was feasible. DuraGen (Integra LifeSciences) was used to cover the dural repair site in all cases. Fibrin glue (Tisseel; Baxter Healthcare Products) was applied in cases with dural defect to prevent further CSF leakage. Additionally, we performed sacral laminoplasty with titanium mesh (Aesculap; Fig. 1) to cover the sacral laminal defect. The titanium mesh was shaped according to the size and contour of the sacral laminal defect and fixed to the sacrum with screws (length 3-5 mm). Finally, the muscle and skin were directly closed in layers using 2-0 Vicryl and 3-0 nylon sutures (Ethicon Inc.). The postoperative condition, radiography, and MRI studies were collected for evaluation. IRB approval was obtained to conduct this case series. Consent was not required.

\section{Results}

Six patients were included in this study (Table 1). All were male. The mean age was 12.0 years, ranging from 4 to 18 years. Four patients (cases $1-4$ ) were diagnosed with congenital sacral myelomeningocele and the lesions had been repaired in the newborn stage. Three of these 4 patients had previously undergone VP shunt placement and 1 of the 3 patients had received additional ETV for hydrocephalus. These 4 patients were diagnosed with retethered spinal cord and progressive dural ectasia herniating out of the sacral laminal defect, confirmed by serial imaging during follow-up periods of $10,9,18$, and 14 years, respectively. One patient (case 5) had lipomyelomeningocele with tethered spinal cord and received detethering surgery at the ages of 6 months and 3.6 years at another hospital. This patient (case 5) presented with CSF leakage as well as a huge subcutaneous pseudomeningocele. The remaining patient (case 6) had a symptomatic Tarlov cyst.

Cases 1-4 underwent detethering surgery, case 5 received repair of CSF leakage, and case 6 underwent repair of the Tarlov cyst. All 6 patients subsequently underwent sacral laminoplasty with titanium mesh using the technique noted above.

TABLE 1. Clinical characteristics of the 6 patients in the case series

\begin{tabular}{|c|c|c|c|c|c|c|c|}
\hline $\begin{array}{l}\text { Case } \\
\text { No. }\end{array}$ & $\begin{array}{l}\text { Age } \\
(\mathrm{yrs})^{*}\end{array}$ & $\begin{array}{l}\text { Underlying } \\
\text { Pathology }\end{array}$ & Level & Previous Surgeries/Age & Associated Pathology/Tx & Presenting Sxs & $\begin{array}{c}\text { FU } \\
\text { (mos) }\end{array}$ \\
\hline 1 & 10 & MMC & S2-3 & MMC repair/newborn & $\begin{array}{l}\text { Hydrocephalus/VP shunt \& } \\
\text { ETV }\end{array}$ & Low-back pain \& tenderness & 31 \\
\hline 2 & 13 & MMC & L4-S3 & $\begin{array}{l}\text { MMC repair/newborn; detethering/ } \\
4 \text { yrs }\end{array}$ & Hydrocephalus/VP shunt & Local tenderness \& enlarging mass & 24 \\
\hline 3 & 18 & MMC & S2-3 & MMC repair/newborn & Hydrocephalus/VP shunt & Low-back pain \& tenderness & 32 \\
\hline 4 & 14 & MMC & S2-3 & MMC repair/newborn & None & Calf \& ankle pain & 13 \\
\hline 5 & 4 & LMMC & L5-S3 & $\begin{array}{l}\text { Detethering/6 mos; re-detethering/ } \\
3.6 \mathrm{yrs}\end{array}$ & None & $\begin{array}{l}\text { Subcutaneous CSF accumulation } \\
\text { (huge pseudomeningocele) }\end{array}$ & 18 \\
\hline 6 & 13 & Tarlov cyst & S1-4 & None & None & Local pain \& tenderness & 37 \\
\hline
\end{tabular}

$\mathrm{FU}=$ follow-up; $\mathrm{LMMC}=$ lipomyelomeningocele; $\mathrm{MMC}=$ myelomeningocele; $\mathrm{Sxs}=$ symptoms; $\mathrm{Tx}=$ treatment.

${ }^{*}$ All patients were male. 

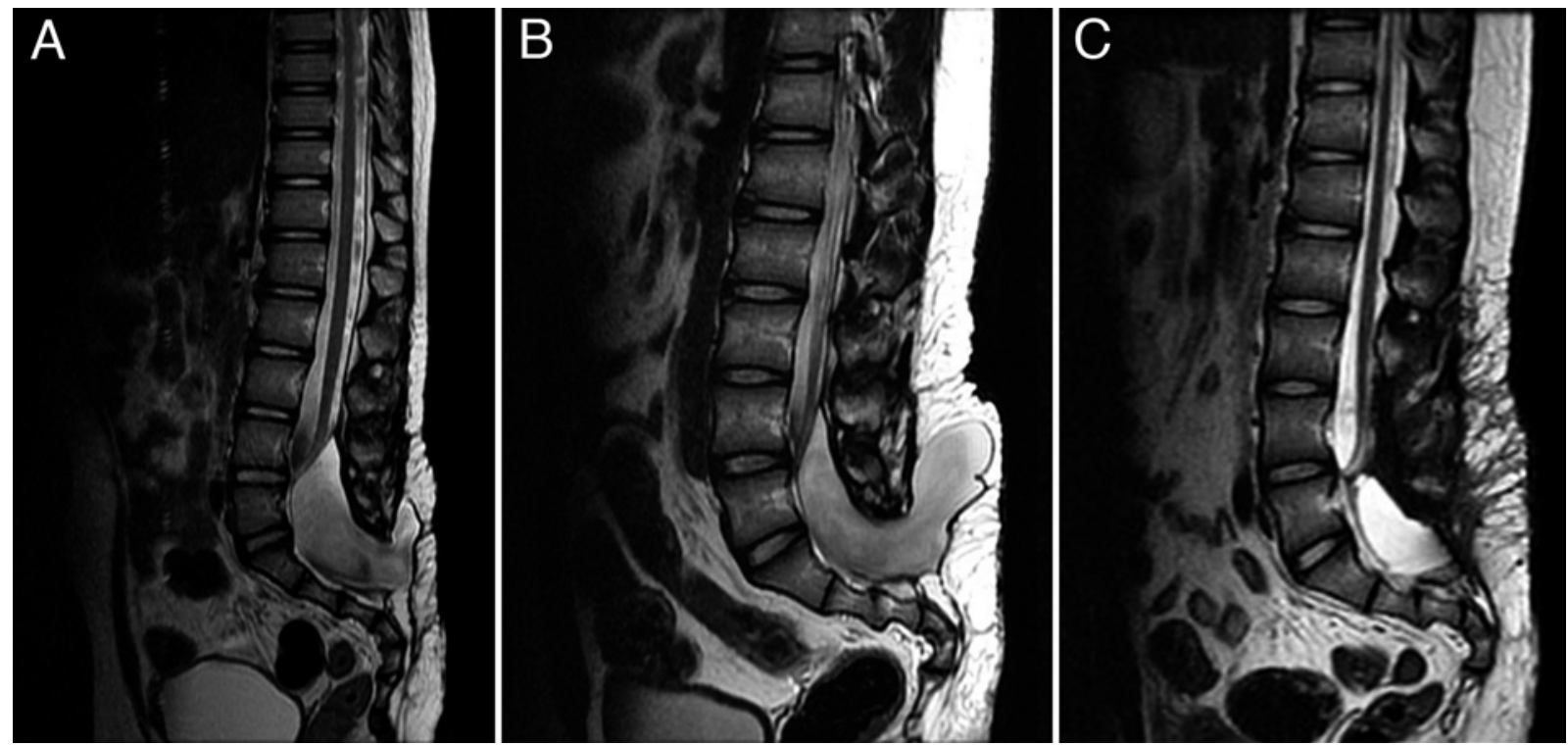

FIG. 2. Case 2. A: Sagittal view of spinal MRI shows a dilated dural sac herniating out from the sacral defect when the patient was 6 years old. B: Sagittal view of spinal MRI shows enlargement of the herniated dural sac when the patient was 13 years old. C: Sagittal view of spinal MRI at 3 months after sacral laminoplasty. The local symptoms disappeared.

During a mean follow-up period of 25.8 months, ranging from 13 to 37 months, all patients reported no local symptoms and no recurrence of dural herniation or CSF leakage. The titanium mesh and screws did not produce artifacts on follow-up MR images and there was no migration or sinking of the mesh and screws on follow-up imaging. In addition, the hydrocephalus in cases 1-3 remained stable postoperatively.

\section{Illustrative Cases}

\section{Case 2}

A 13-year-old boy underwent repair of myelomeningocele 1 day after birth in another hospital. A VP shunt was also placed for the management of hydrocephalus. When he was 4 years old, he underwent L4-S2 laminoplasty with autologous graft, detethering surgery, and excision of a dermoid cyst. In that surgery, the abnormally thin dura was repaired primarily and reinforced with an autologous fascia graft and DuraGen. After repairing the dura, the hypoplastic laminae removed during the laminotomy were returned to their place and fixed with simple interrupted silk sutures. However, during follow-up in the subsequent 9 years, serial MR images (Fig. 2A and B) disclosed progressive sacral dural ectasia herniating out of the sacral lamina, and a retethered spinal cord. Clinically, he suffered from a bulging sacral mass and local tenderness.

Detethering surgery was performed again. Intraoperatively, a fibrotic and enlarged dural sac and arachnoid membrane were noted, compatible with the diagnosis of dural ectasia. After detethering surgery, redundant fibrotic dura was excised and the durotomy was closed primarily. Sacral laminoplasty with titanium mesh was performed.

On follow-up, the MRI performed 3 months postoperatively (Fig. 2C) no longer showed dural ectasia herniating out of the titanium mesh, and no more sacral tenderness has been reported after the surgery.

\section{Case 5}

A 4-year-old boy with lipomyelomeningocele had undergone 2 detethering and repair surgeries when he was 6 months old and 3.6 years old. After the second surgery, he presented to our institute due to an enlarging subcutaneous soft mass in the sacral area. MRI disclosed a huge pseudomeningocele (Fig. 3 left). Intraoperatively, a very wide laminar defect that resulted from a previous laminectomy was found. A piece of artificial dura was identified intraoperatively. We speculate that the previous surgeon used the extensive dural graft to prevent retethering of the spinal cord. A longitudinal leakage site approximately 1 $\mathrm{cm}$ in length between the dura and artificial dura due to
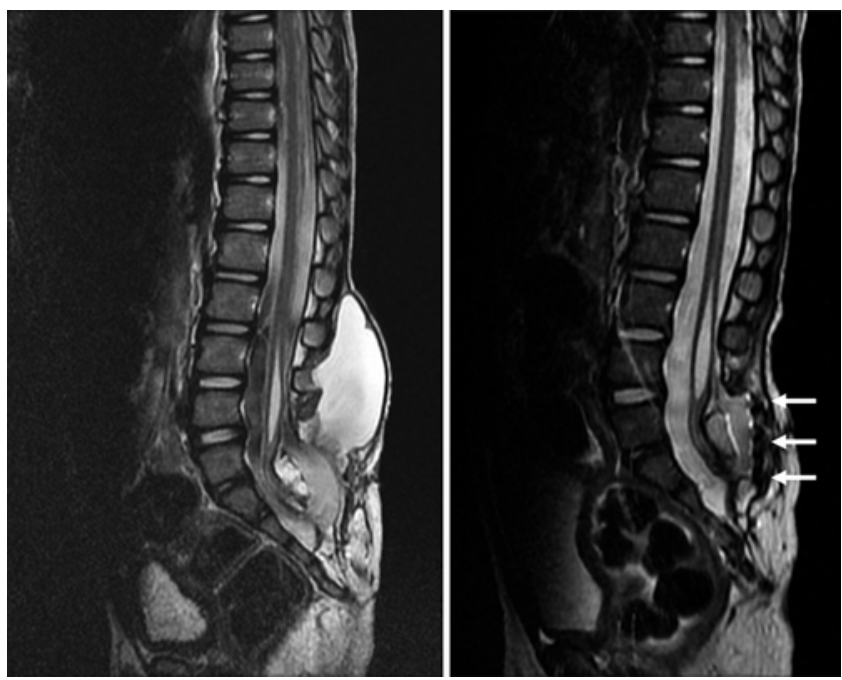

FIG. 3. Case 5. Left: Sagittal view of preoperative spinal MRI shows a huge pseudomeningocele. Right: Sagittal view of spinal MRI at 18 months after sacral laminoplasty shows there is no artifact produced by the titanium mesh (arrows). 


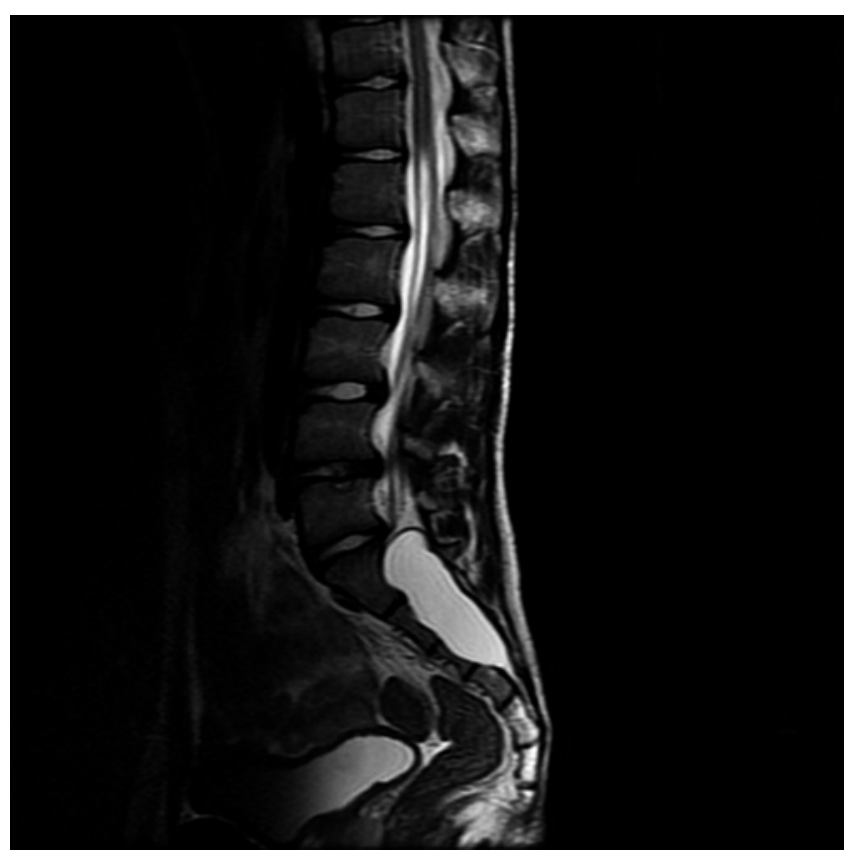

FIG. 4. Case 6. Preoperative sagittal view of spinal MRI of a huge Tarlov cyst.

stitch loosening was identified at the right posterolateral side of the thecal sac. The defect between the dura and the artificial dura was primarily repaired with 5-0 Prolene sutures, and augmented with Tisseel and DuraGen over the suture line. Titanium mesh was used to provide further support for the Tisseel and DuraGen. There was no recurrence of pseudomeningocele on follow-up MR images (Fig. 3 right).

\section{Case 6}

A 13-year-old boy presented with sacral dimpling and local tenderness. MRI revealed a large sacral cyst with sacral bone erosion (Fig. 4). Surgery was performed for the large symptomatic Tarlov cyst. Intraoperatively, the sacral lamina was found to have been eroded by the arachnoid cyst and became paper-thin; thus, the lamina could not be preserved. Following laminectomy, the thin, transparent cystic wall was opened and dissected to expose a tract connecting the cystic cavity to a small dural defect at the left S3 nerve sleeve. The small dural defect was repaired using 7-0 Prolene sutures and reinforced with paraspinal muscle graft, Tisseel, and DuraGen. Laminoplasty with titanium mesh was performed in the same way as mentioned previously. After surgery, the local tenderness disappeared and no recurrence of the Tarlov cyst was noted.

\section{Discussion}

A symptomatic cyst in the sacral area can result from a variety of conditions, of which spina bifida is a very important disease. ${ }^{11}$ Our case series presents 4 patients with repaired myelomeningocele who experienced retethered spinal cord and progressive dural ectasia; 1 patient with lipomyelomeningocele who had previously undergone detethering surgery and duraplasty, and subsequently devel- oped CSF leakage and a huge pseudomeningocele; and 1 patient with a newly diagnosed symptomatic Tarlov cyst. Although these cases have different underlying diseases, they share a similar feature of expansile CSF accumulation in the sacral area. This vulnerability to fluid accumulation can be well explained by the fact that the sacrum not only has the thinnest coverage of soft tissue, but also is the most gravity-dependent part in the spine. ${ }^{13}$ As a result, complications related to CSF accumulation after repair of spina bifida are concerning. ${ }^{10}$ It has been reported that as many as $14.6 \%$ of cases with repaired myelomeningocele were complicated by subcutaneous CSF accumulation and $6.25 \%$ of patients suffered from postoperative CSF fistula. ${ }^{8}$ Case 2 received a piece of autologous fascia to reinforce the abnormally thin dura and underwent laminoplasty with his hypoplastic, eggshell-like autologous sacral lamina during the second detethering surgery when he was 4 years old. However, he gradually developed dural ectasia herniating out of the sacral defect during the subsequent 9-year period. In the most recent detethering surgery, the autologous sacral laminoplasty seemed resorbed and the reinforced dura was intact, thick, fibrotic, and dilated. In our series, cases 1-4 shared similar diagnoses and intraoperative findings 10, 9, 18, and 14 years, respectively, after previous detethering surgery. This is a very good example showing the power of CSF and gravity, both of which can gradually dilate an intact dura and cause problems. In contrast, case 5 is a typical case of CSF leakage and very large pseudomeningocele formation.

Traditionally, the lamina was not viewed as an essential structure for spinal integrity, and laminectomy was a very common procedure in different kinds of spinal surgery. ${ }^{9}$ However, more and more evidence has revealed that removal or absence of laminae may predispose patients to some conditions, of which progressive kyphosis or scoliosis is the most well-known, especially in the pediatric patient population. ${ }^{1}$ Conversely, the relationship between CSF leakage and laminectomy is discussed less often. A recent meta-analysis comparing laminectomy and laminoplasty for intradural spinal tumor surgery revealed a significantly lower rate of postoperative CSF leakage in patients with laminoplasty. ${ }^{14}$ Although the definitive mechanism is still unclear, it is proposed that laminoplasty not only provides further support and cover to the dural closure site, but also prevents postoperative adhesions between the closure site and surrounding soft tissue. These mechanisms may contribute to the decrease in CSF leakage. ${ }^{14}$ Furthermore, we propose that rigid sacral laminoplasty can also prevent dural ectasia caused by CSF and gravity, and subsequent dural herniation out of the sacral defects, as in cases 1-4. None of our cases showed postoperative CSF leakage or recurrence of the lesions after laminoplasty with titanium mesh.

Rigid sacral laminoplasty not only resolves postoperative dural ectasia or pseudomeningocele, but also should be considered in other cases with sacral CSF-containing lesions that have a high risk of postoperative CSF leakage. In case 6 , although the small dural defect was repaired with sutures and a muscular graft, the risk of CSF leakage was still high due to the abnormally thin dura at the suture site, large dead space, and unpreservable sacral lamina. 
Therefore, rigid sacral laminoplasty was performed to provide a support for compressive dressing after surgery, and no cyst recurrence was noted. After reviewing other publications, we found that Smith et al. also reported 18 cases of Tarlov cysts treated with open fenestration and laminoplasty. Only one of the cases had postoperative CSF leakage, and none reported cyst recurrence at the 1-year follow-up evaluation. ${ }^{13}$

In addition to dural ectasia, 3 cases with repaired myelomeningocele (cases 1-3) in our series presented with local tenderness. Although $15 \%-30 \%$ of patients with repaired myelomeningocele will develop spinal cord retethering as well as tethered cord syndrome, and thus may present with low-back pain, ${ }^{2}$ local tenderness in our cases could not be explained by a tethered spinal cord. In our experience, this local tenderness is more similar to the symptoms caused by postlaminectomy syndrome. Postlaminectomy syndrome can present with severe low-back pain and local tenderness, with or without radiation and paresthesia. ${ }^{12}$ This syndrome is still a challenge for spine surgeons to overcome after decades of development in modern spine surgery. The adhesion and fibrosis between the dura and surrounding soft tissue are important factors contributing to this syndrome. ${ }^{12}$ Furthermore, if there is an adhesion among nerve, dura, and soft tissue, such as in cases with repaired myelomeningocele, the conditions may be more complicated.

To decrease adhesion formation, laminoplasty is an effective method. Cobb and Boop reported a comparison between lumbar-sacral laminectomy and laminoplasty in 35 patients who had undergone selective dorsal rhizotomy. ${ }^{4}$ Four of the 15 patients with laminectomy developed significant back pain of musculoskeletal origin, but none of the 20 patients with laminoplasty developed such back pain. ${ }^{4}$ In our case series, none of the 6 cases presented with local tenderness or low-back pain after laminoplasty with titanium mesh.

Five cases (cases 1-5) in our case series presented with congenital defects of the sacral laminae, and 1 case (case 6) presented with a paper-thin lamina that could not be preserved during surgery. We do not routinely use titanium mesh in surgery for spina bifida, pseudomeningocele, and Tarlov cysts. Considering the total number of 383 surgeries for spinal bifida and Tarlov cyst in the past 20 years (1998 to approximately 2019) that were performed by the senior pediatric neurosurgeon (M.F.K.), sacral laminoplasty has rarely been needed. However, in cases with defective sacral lamina that have progressive dural ectasia, postoperative pseudomeningocele with treatment failure, postoperative refractory local symptoms, or high risk of postoperative CSF accumulation, laminoplasty with an artificial graft should be considered.

Titanium, with both rigidity and biocompatibility, has been broadly used as a safe and effective material for spinal reconstruction. The interpretation of follow-up MRI was also not hindered by minimal artifacts resulting from the titanium mesh. In addition, cervical laminoplasty with titanium mesh has also been reported recently as a novel and safe technique.$^{15}$ Regarding the use of titanium mesh in the developing spines of pediatric patients, in children older than 10 years of age, sacral instrumentation with screws and rods has been reported as a standard procedure with an instrumentation failure rate as low as $1.3 \%$. In a younger child, the spinal canal grows to approximately $90 \%$ of its definitive size by age $3-5$ years. ${ }^{6}$ Therefore, it is important to emphasize the use of sacral laminoplasty with titanium mesh in highly selected patients who are older than 3 years and are confirmed to have symptomatic progression of dural ectasia, pseudomeningocele, or other expansile cystic lesions in the sacral region. In our case series, no dislocation or deformity of the titanium mesh was documented during follow-up. It is applicable with minimal side effects in selected cases.

\section{Limitations}

There were several limitations to our study. First, although all of our cases achieved satisfactory outcomes, the number of cases in our series is low and the followup period is relatively short for pediatric patients. Because titanium mesh is not routinely used in pediatric patients, lack of a control group with similar presentations is also a limitation of our study. With further accumulation of cases and longer follow-up periods, the safety and efficacy of sacral laminoplasty with titanium mesh will become clear.

Second, it is not clear whether implantation of rigid titanium mesh into a neonate will limit normal growth of the sacrum. Therefore, we reserved this procedure for older children who had stable spine growth and good dural quality to prevent erosion of the underlying dura. The age limitation of this procedure requires more studies.

\section{Conclusions}

Sacral laminoplasty with titanium plays a role in selected patients who have defective sacral laminae complicated by progressive dural ectasia, postoperative pseudomeningocele, Tarlov cyst, or other CSF-containing lesions. This procedure may also relieve local symptoms resulting from dural adhesion. Nonetheless, we do not suggest that this procedure be performed routinely in all patients, especially those who are younger than 3 years of age.

\section{References}

1. Ahmed R, Menezes AH, Awe OO, Mahaney KB, Torner JC, Weinstein SL: Long-term incidence and risk factors for development of spinal deformity following resection of pediatric intramedullary spinal cord tumors. J Neurosurg Pediatr 13:613-621, 2014

2. Beuriat PA, Poirot I, Hameury F, Szathmari A, Rousselle C, Sabatier I, et al: Postnatal management of myelomeningocele: outcome with a multidisciplinary team experience. World Neurosurg 110:e24-e31, 2018

3. Caldarelli M, Boscarelli A, Massimi L: Recurrent tethered cord: radiological investigation and management. Childs Nerv Syst 29:1601-1609, 2013

4. Cobb MA, Boop FA: Replacement laminoplasty in selective dorsal rhizotomy: possible protection against the development of musculoskeletal pain. Pediatr Neurosurg 21:237242, 1994

5. Epter RS, Helm S II, Hayek SM, Benyamin RM, Smith HS, Abdi S: Systematic review of percutaneous adhesiolysis and management of chronic low back pain in post lumbar surgery syndrome. Pain Physician 12:361-378, 2009

6. Hinck VC, Hopkins CE, Clark WM: Sagittal diameter of 
the lumbar spinal canal in children and adults. Radiology 85:929-937, 1965

7. Jain A, Sullivan BT, Kuwabara A, Kebaish KM, Sponseller PD: Sacral-alar-iliac fixation in children with neuromuscular scoliosis: minimum 5-year follow-up. World Neurosurg 108:474-478, 2017

8. Januschek E, Röhrig A, Kunze S, Fremerey C, Wiebe B, Messing-Jünger M: Myelomeningocele-a single institute analysis of the years 2007 to 2015 . Childs Nerv Syst 32:1281-1287, 2016

9. Kepler CK, Schroeder GD, Hollern DA, Chapman JR, Fehlings MG, Dvorak M, et al: Do formal laminectomy and timing of decompression for patients with sacral fracture and neurologic deficit affect outcome? J Orthop Trauma 31 (Suppl 4):S75-S80, 2017

10. Kobraei EM, Ricci JA, Vasconez HC, Rinker BD: A comparison of techniques for myelomeningocele defect closure in the neonatal period. Childs Nerv Syst 30:1535-1541, 2014

11. Patnaik A, Mahapatra AK: Complex forms of spinal dysraphism. Childs Nerv Syst 29:1527-1532, 2013

12. Paul AR, Kumar V, Roth S, Gooch MR, Pilitsis JG: Establishing minimal clinically important difference of spinal cord stimulation therapy in post-laminectomy syndrome. Neurosurgery 81:1011-1015, 2017

13. Smith ZA, Li Z, Raphael D, Khoo LT: Sacral laminoplasty and cystic fenestration in the treatment of symptomatic sacral perineural (Tarlov) cysts: technical case report. Surg Neurol Int 2:129, 2011
14. Sun S, Li Y, Wang X, Lu G, She L, Yan Z, et al: Safety and efficacy of laminoplasty versus laminectomy in the treatment of spinal cord tumors: a systematic review and meta-analysis. World Neurosurg 125:136-145, 2019

15. Wicaksono AS, Manusubroto W: Short-term clinical evaluation of enhanced unilateral open-door laminoplasty using titanium mesh. Asian Spine J 12:810-816, 2018

\section{Disclosures}

The authors report no conflict of interest concerning the materials or methods used in this study or the findings specified in this paper.

\section{Author Contributions}

Conception and design: Kuo, Chen, Yang. Acquisition of data: Kuo, Chen, Chou. Drafting the article: Chen. Critically revising the article: all authors. Reviewed submitted version of manuscript: all authors. Approved the final version of the manuscript on behalf of all authors: Kuo. Administrative/technical/material support: all authors. Study supervision: Kuo.

\section{Correspondence}

Meng-Fai Kuo: National Taiwan University Hospital, National Taiwan University College of Medicine, Taipei, Taiwan. mfkenator@gmail.com. 